\title{
A Critical Review on the Beginning, Recent Advancement and Upcoming Challenges of Green Chemistry
}

\author{
Sameer Quazi ${ }^{* *}$, Aleesha A ${ }^{2}$, Christina Elsa Thomas ${ }^{1}$ \\ ${ }^{1}$ Department of Genetics, Indian Academy Degree College, Hennur Cross, Bangalore, Karnataka, India \\ ${ }^{2}$ Department of Chemistry, Indian Academy Degree College, Hennur Cross, Bangalore, Karnataka, India
}

\author{
DOI: $10.36348 /$ sijcms.2020.v03i06.001 \\ | Received: 21.07.2020 | Accepted: 30.07.2020 | Published: 09.08.2020 \\ *Corresponding author: Sameer Quazi
}

\section{Abstract}

Throughout a long time, green chemistry (GC) reviled how a basic scientific methodology and advanced practice can enhance the safe output to human life and the environment without compromising the desired outcomes. For this, advancements in scientific processes have been made in the field of designing safer reagents and solvents, advancement in catalysis and possible development of the renewable feedstock. From the chapters of the past, future chemists are being taught and trained to a wider concept of green chemistry to practice and increase awareness towards human as well as environmental impact. Green Chemistry practice is in high demand and the adherence to the 12 principles of the Green Chemistry concept is growing rapidly. A need for great change in policy, rules and regulations that will force industries, research institutes, academics, and others are still needed more than ever. Moreover, better encouragement, awareness and making an individual person responsible to adapting to a Green Chemistry concept in a real practical way, are needed. Green actions are always louder than green words.

Keywords: Green Chemistry, catalyst, Organic synthesis, challenges, Non-toxic approach, environment benign.

Copyright @ 2020: This is an open-access article distributed under the terms of the Creative Commons Attribution license which permits unrestricted use, distribution, and reproduction in any medium for non-commercial use (NonCommercial, or CC-BY-NC) provided the original author and source are credited.

\section{INTRODUCTION}

The Green Chemistry is a broader concept that enhances the proper design of the chemical product and the synthesis process in a whole to eliminate or to reduce the generation as well as the use of the hazardous substance to the human, animals and the environment where we live. The hazard includes the broad context like physical- explosion, flammability, toxicological- mutagens, carcinogens, etc., and the global- climatic changes, ozone layer depletion, other environmental pollutions, and exposures, etc.

From the time since the concept of Green Chemistry was stated by Paul Anastas and John Warner in 1990s, so many advancements have taken place and going on to address the global problems with hazardous chemicals, and synthetic methods. The effects of hazardous substances to our environment, water, air, food, agriculture, climatic changes and many more hazards in each and every corner of the environment alerts us more and more to focus and practice greener concept. For sustainable chemistry, we should always need to think of safer and better options. Many examples in our surrounding scientist made it successful like the replacement of chlorofluorocarbons in insulating foams with safer one prevents a great risk of its associated effects to our ozone layer and a world as a whole. Many examples in energy source like decreased use of fossil fuels and the development of safer pesticides made big changes. Although a lot of approaches is doing from many sides it's not enough. Each and every individual need to think this globe, as their own home, sleeping room, kitchen then only it will make us more and more responsible to find better and safer options, reduce of hazards, reuse of some items to decrease its exposure and productions, etc. As the GC is intentionally designed and a lot of approaches are set with the principal but there is always lacking between the principle and the practice. Many approaches to green chemistry synthesis are developed and going on rapidly.

\section{Guiding Principles of Green Chemistry}

The 12 principles of GC guide us to design, develop and practice a greener concept. These sets of principles alert the fundamental approach to be done to achieve GC goals. From the past decades of practice in this approach continued in the present and will be so far in the future because it's very important for sustainable chemistry. 
Below mentioned are the 12 principles of green chemistry

1. Prevention: It is always better to prevent the generation of waste rather than to treat or clean up after its generated.

2. Atom Economy: The good Synthetic methods should always be designed to maximize the utilization of all reactants used in the process into the desired final product.

3. Less Hazardous Synthesis: As much as possible the synthetic methods should be developed to use and produce less toxic, less hazardous to the health as well as to the surrounding.

4. Designing Safer reactants, solvents and other chemicals: The chemical substances should be designed in such a way that their desired function remains but in minimized quantity or with no toxicity.

5. Safer Solvents and Auxiliaries: The used quantity of solvents and other agents like separating agent's costs are higher so it's better to practice the safer one and reduce the unnecessary use.

6. Design for Energy Efficiency: As much as possible the synthetic methods should be developed to occur at ambient temperature and pressure in good yield. The use of high temperature as well as low temperature generates excess energy burden and the correlated problems.
7. Use of Renewable Feedstock: Whenever possible the use of renewable reagents, raw materials or feedstock's should be practiced.

8. Reduce Derivatives: The reduction of steps in synthesis will automatically use fewer reagents, less time, less energy and overall less risk, hazards and less generation of waste. So the unnecessary modification with using blocking groups, protecting and deprotecting groups, etc. should be reduced as much as possible.

9. Catalysis: The use of a proper catalyst will reduce the use of excess stoichiometric reagents so reduces ultimate waste and hazards.

10. Design for Degradation: At the end of their function, they should be designed in such a way that will allow degradation and convert to a nontoxic substance to the human as well as to the environment.

11. Real-time analysis for Pollution Prevention: Some analytical methodologies are developed and more is deemed to be developed further so we can observe at a real time that will prevent the generation of further hazards.

12. Inherently Safer Chemistry for Accident Prevention: Always we should keep in a mind not to use, or reduce the hazardous, explosive, frequent accident causing substances and replace it with safer one which will minimize toxicity, prevent accidents, explosion, and fires, etc.

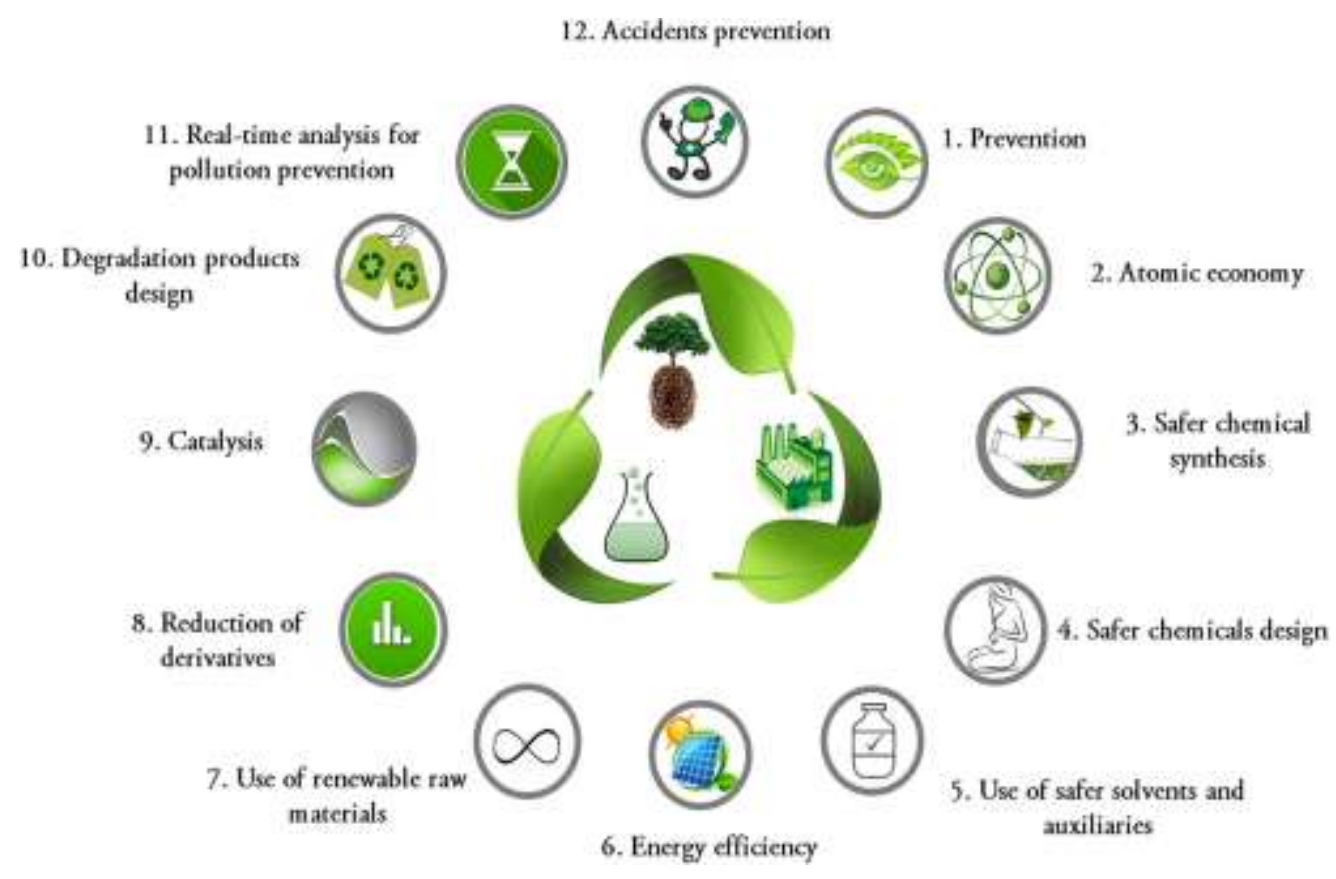

\section{Beginning of Concept of Green Chemistry}

In the history of chemistry for the very first time, Paul Anastas and John Warner were those who generated the concept of GC in the 1990s whose core meaning was to apply methodology, technique, think always in detail about process and possible options that how we can reduce or completely eliminate the formation of hazardous substances, byproducts, feedstock, reagents, solvents and other waste that are hazardous to us as well as the environment where we 
live [11]. Specially in the synthetic chemistry, the volume of solvents being used is higher so to overcome this situation many greener concepts are developed like by using less hazardous solvents, reduce the amount, substitute with other methods like solid phase synthesis, using a eutectic mixture or water-based reactions, etc [12]. Some big company made their solvent using guide to reduce the associated hazards. Based on their toxicity they are categorized as preferred (green), usable (yellow) and undesired (red) [13]. A chemo-metric and multi-criteria decision analysis was elaborated by Marek et al for 151 solvents [14]. The pollution prevention act 1990 by the USA leads the global scenario towards the reduction of waste generation as the highest priority [15]. This alerts to a diverse sector and this recognition extended to the chemists and related designer personalities and to the institutions, industries and corporate bodies as a whole. In 1991 EPA released a green chemistry program, alternative synthetic methods, etc [1, 11]. Then in 1992 National foundation launched a program on the environmentally benign synthesis and started a partnership with the EPA in 1993. After the US green chemistry program being officially adopted by EPA, it became a central point for major activities throughout the USA. At the same time, many nations grow to the concept simultaneously as well as beginning with independently. First half of 1990, the UK and Italy launched key initiatives in GC. Many industries, institutions, researchers accepted green chemistry programs and concepts. At the end of the same year, Japan organized the Green and Sustainable Chemistry Network (GSCN) to promote research and development with the same topic theme. The first Journal of green chemistry edition was sponsored by the Royal Society of Chemistry and published in 1999. The approach to be accepted by the global researcher, industry and institutions took some time and still growing fast. The US presidential GC challenge award was launched in 1995 to recognize the accomplishment in the field of GC by academia, institutions, industry, and government.

\section{Recent Advancements \& Upcoming Challenges}

After its beginning in 1991, it is growing significantly throughout the world in the field of chemistry. Although the Green Chemistry concept is widely accepted and vibrate researchers, students, faculty, university, industry, policymakers and in general society but many obstacles are also on it. These Advancements and Challenges and be classified in three major categories:

\section{In Research}

In research many conferences, research, other academic activities, awards, production, adoption by industry and researcher and many more are being held as green chemistry is a social movement for the change $[17,18]$. Education has a greater role to teach properly about the concept and practice of green chemistry [19]. The research laboratory is organizing in a well- equipped way to prevent from chemical exposure, adoption of more safer technologies, use of greener feedstock practice are increasing $[11,20]$. Mostly to the developed nation they are adapting very fast. The recently established institution is adopting recent technologies matched with green chemistry principle. More advanced research is still to be adopted in the core areas like in renewable feedstock and other bio-based transformation, design for degradability and structural design. The generated waste should be handled and treated safely to dispose properly. Some renewable feedstocks like e.g. $\mathrm{CO} 2$ are utilizing in various purposes. The polymer that is derived from carbohydrate feedstocks like corn and soy are seen in automobile and food packing. To convert the glucose to a biodegradable polymer, the use of microbial fermentation is increasing. Mostly the use of less toxic solvents or solvent-free synthesis is being more focused. Some large company has categorized the solvent based on their toxicity and labeled as Green, Yellow and Red. The use of water as a reaction solvent is focusing more and many reactions are done in water with using a proper catalyst, using phase-transfer catalyst and optimized reaction conditions.[30, 31] Even the water sensitive reactions like Grignard reaction can also run in an aqueous medium using various metal like zinc and indium [32-35]. The use of ionic liquid also increases due to its negligible vapor pressure and their enhanced polar system attracts researcher to perform diverse reactions [36-38]. The fundamental pillar of GC remained as catalyst development which decreases reaction time, temperature, solvents, reagents, better yields, nontoxic and many more. A lot of researchers are involved in developing a proper catalyst. As greater than $98 \%$ of organic chemicals are from petroleum products. So to make sustainable chemistry we need to search renewable sources and many progress, research is going on like utilizing carbohydrate as a feedstock for various chemical synthesis and other polymer chemistry [11]. Some commercially available chemicals like chitin derived from natural Shells from crabs and other sea life, which can be further converted to chitosan, a valuable biopolymer used in various kinds of application in synthesis $[39,40]$. The use of genetically modified E. coli to convert glucose to catechol and recombinant Saccharomyces yeast can convert both the xylose and glucose to ethanol [11]. The use of cascade reaction [41], biomimetic approaches [42] and molecular self-assembling reaction always remain core corner for GC.

The proper analytical detection methods always remained a central role for detecting, monitoring and measuring environmental contaminants. For this many advanced analytical instruments are developed and developing. If we are success to apply the analytical method in real time monitoring especially in feedstock utilization, then we will be able to detect the progress in updated time and control further action if not going 
well, generating more hazardous chemicals, etc [11, 43].

Designing a safer chemical always remains a focused point and many pharmaceutical companies have already got success on it and many researchers are going on to develop a safer option. Success in the solvent, pesticide, surfactants, polymer, and dyes are some better example of green chemistry approach.

\section{Challenge in Research}

Describing each challenge in this category is not possible as we know a lot of challenges are in this field but some of the major challenges in research are:

- Schooling researcher in a better way with recent advancement and rapidly adapting green products and services.

- Utilizing energy rather than the materials in transformation.

- Optimization in all sectors with solvents, catalyst, and others.

- Development of a toolbox for various synthetic approaches that are benign to environment, health and promote the atom economy.

- Harmful additive free design of polymer and plastics and developing other biodegradable product instead of plastics.

- Designing for reuse and recycle for all substances.

- Can be reused but due to the negligence of the researcher, they are just throwing it.

- The development of non-material intensive and no combustion energy source.

- Adapting to modern safety technologies and using greener reagents, solvents throughout the world research laboratory.

- Selective reaction with reactive functionality without using protecting groups.

- Not having enough availability options regarding to reagents, solvents, instruments and many more to adapt to green chemistry.

\section{In Education}

Education has and will always be a milestone to change society. To be a better chemist and work on ethics, the better education always plays a crucial role. So the GC now vibrates the academic institutions, professors, researchers, and students. Many GC concepts are incorporated into the curriculum to improve student's better understanding. Many rules and regulation by the government are tightening to adapt to the GC principal in an academic research lab. Many leadership programs are being held by Royal chemical society, American chemical society, German and Japan chemical society which played a great role to make it better, and understandable. Mainly the GC initiatives include literature, textbooks, some important case studies, experiments at the laboratory, related and other student organization, faculty training, school teacher training, other resource tools, seminar and symposia related to it, and other professional workshops. Now the undergraduate, graduate, Ph.D. program in GC are established.

\section{Challenge in Education}

Education is core to change all. The future leader in the industry or any institution moved there after their education. So, giving proper education to the student in an academic institution is core. Some of the needed point and challenges under this topic are listed below

- Recognition of the toxicity, hazards with relation to the physical and chemical properties via molecular structure in a systematic way.

- Adapting recent technologies, practically utilizing green chemistry principle in the laboratory during the experiment and providing detailed concept about it.

- Thinking and further practice of atom economy approach.

- Providing a better understanding of toxicity and molecular hazards.

- Applying GC topic in institutional as well professional certification exam.

- Repeated seminar, symposia, discussion, awards about GC within the institution and exposure to the greater stage to numerous students and introducing benefits of adopting green chemistry.

\section{In other parts}

Above discussed are about the role of education and research in green chemistry. Here other many factors are related to tackling with the GC principle to practice. As we know the basic of GC is, we should be able to change the perspective and thinking that will force us to adopt GC principle throughout the life. In regard to the community, chemical society, journals, books, symposia, other award recognition, governmental and non-governmental institution's role are much important. With the aim "to promote green chemistry research, education, and outreach" in the mid-1990s the GCI (green chemistry institute) begin and opened many chapters in different nations. It is working to promote awareness and many programs as described above. The other network like GC network in the UK, Japan, and Italy serves in a similar way and also involves in industrial as well as in an educational journal. To focus peerreviewed research and other advancements in the field of GC, the Royal Society of Chemistry launched Green chemistry journal, and other similar journals are increasing in number. Many green chemistry conferences are held in different countries regularly.

\section{Challenge in implementation}

Whatever the principle we develop, the implementation is a core thing to signify the principle to practice. Although, we developed many greener technologies, chemicals, and many greener alternatives 
it doesn't guarantee that it will be adapted rapidly and completely. For this, we need to do many things some of the challenges under this category are pointed below:

- Adaptable regulation and flexibility.

- No, reduced, or incentives in tax who use cleaner technologies and green reagents.

- Research program and collaborative work among the industries, academic institutions, research institutes, and government for technology transfer.

- Extension of patent time for optimization of cleaner process.

'Based on above Green Chemistry principle many countries, industries, institutions and individuals are carrying out their action, activities, policies and overall direction to shift to the greener concept from use, reuse to the process and finalization. Below sentences discusses the greener alternative products.'

\section{Greener alternatives}

It could be products, processes and many more that will enhance us to shift to a greener one. Like the commercial site, the Sigma-Aldrich listed as a "Greener Alternative Products" that aligned with the 12 principles of GC. It is categorized into different groups like Biobased greener alternatives, lab essentials, building blocks, organometallics, synthetic reagents, life sciences, catalysis, and solvents.

\section{Greener Services}

This is very important because for a greener approach, we do not need to speak. The green action will always win over the green louder voice.

\section{Awards in Green Chemistry}

- Presidential Green Chemistry Challenge Awards in the US.

- The Canadian Green Chemistry Medal.

- Green Chemical Technology Awards by Crystal Faraday in the United Kingdom.

- GSC awards program by the Green \& Sustainable Chemistry Network in Japan.

- Australia's Green Chemistry Challenge Awards by The Royal Australian Chemical Institute (RACI).

- INCA award in Italy

Although many things are being tried and approaches are increasing, still there is a need for some strict rules and regulations to stop misuse, negligence, and many more. We need to provide a repeated encouraged education about chemical hazards, use, handling, renewable approaches, carefulness, safety and many more things beginning from children to higher grade students through the curriculum. That will repeatedly strike their mind not to misuse, not to be careless and others and generate responsibility towards the environment. If public awareness is high and cultured motivation, it will lead to a better adaptation to the greener concepts and approaches.

\section{Some green chemistry related journals}

- Green chemistry

- Green chemistry letters and reviews

- RSC Green Chemistry

- ChemSusChem

- Green processing and synthesis

- Green letters

- Current opinion in Green and Sustainable Chemistry

- Electronic green journal

- International journal of green energy

- ACS Sustainable Chemistry \& Engineering

\section{CONCLUSION}

To get sustainable chemistry, the growth of GC over the past decades should be accelerated more towards the diverse sector of chemistry from education, research to core practice and adaptation by the industry in greater aspects. When we heartily practice the basic 12 principles of green chemistry, we may not need to worry about the consequences and have a greener environment in the future. We should make it our everyday practice and natural reflection. For that, we need to grow future chemists with good moral knowledge of GC. For a small lab if a researcher did some malpractice, it could be seen as a small but let us think in a global scenario, there are millions of chemists who are working every day and a mistake made by a single person per day effects in a wider way. So, let us take a step and be responsible for ourselves.

Conflict of Interest: The author declares no conflict of interest.

\section{REFERENCES}

1. Anastas, P., \& Eghbali, N. (2010). Green chemistry: principles and practice. Chemical Society Reviews. 39(1):301-312.

2. Linthorst, J. (2010). An overview: origins and development of green chemistry. Foundations of chemistry. 12(1): 55-68.

3. Badami, B. V. (2008). Concept of green chemistry. Resonance. 13(11): 1041-1048.

4. Marshall, V. C. (1987). Major chemical hazards.

5. Urben, P. (2017). Bretherick's handbook of reactive chemical hazards. Elsevier.

6. Tang, S. L., Smith, R. L., \& Poliakoff, M. (2005). Principles of green chemistry: Productively. Green Chemistry. 7(11): 761-762.

7. Glavič, P., \& Lukman, R. (2007). Review of sustainability terms and their definitions. Journal of cleaner production. 15(18): 1875-1885.

8. Sekiya, A., \& Misaki, S. (2000). The potential of hydrofluoroethers to replace CFCs, HCFCs and PFCs. Journal of Fluorine Chemistry. 101(2): 215221. 
9. DeVito, S. C. (2016). On the design of safer chemicals: A path forward. Green Chemistry. 18(16): 4332-4347.

10. Li, C. J., \& Trost, B. M. (2008). Green chemistry for chemical synthesis. Proceedings of the National Academy of Sciences. 105(36): $13197-$ 13202.

11. Anastas, P. T., \& Kirchhoff, M. M. (2002). Origins, Current Status, and Future Challenges of Green Chemistry. Accounts of Chemical Research. 35(9): 686-694.

12. Sheldon, R. A. (2005). Green solvents for sustainable organic synthesis: state of the art. Green Chemistry. 7(5): 267-278.

13. Byrne, F. P., Jin, S., Paggiola, G., Petchey, T. H., Clark, J. H., Farmer, T. J., ... \& Sherwood, J. (2016). Tools and techniques for solvent selection: green solvent selection guides. Sustainable chemical processes, 4(1), 7.

14. Tobiszewski, M., Tsakovski, S., Simeonov, V., Namieśnik, J., \& Pena-Pereira, F. (2015). A solvent selection guide based on chemometrics and multicriteria decision analysis. Green Chemistry, 17(10), 4773-4785.

15. Burnett, M. L. (1998). The Pollution Prevention Act of 1990: a policy whose time has come or symbolic legislation? Environmental management. 22(2): 213-224.

16. Clark, J. H. (2006). Green chemistry: today (and tomorrow). Green Chemistry. 8(1):17-21.

17. Woodhouse, E. J., \& Breyman, S. (2005). Green chemistry as social movement? Science, Technology, \& Human Values. 30(2): 199-222.

18. Poliakoff, M., Fitzpatrick, J. M., Farren, T. R., \& Anastas, P. T. (2002). Green chemistry: science and politics of change. Science, 297(5582), 807810.

19. Hjeresen, D. L., Boese, J. M., \& Schutt, D. L. (2000). Green chemistry and education. Journal of Chemical Education. 77(12): 1543.

20. Dicks, A. P. (2016). Green organic chemistry in lecture and laboratory. CRC Press.

21. Gielen, D. (1995). Toward integrated energy and materials policies?: A case study on $\mathrm{CO} 2$ reduction in the Netherlands. Energy Policy. 23(12): 1049-1062.

22. Chauvier, C., \& Cantat, T. (2017). A Viewpoint on Chemical Reductions of Carbon-Oxygen Bonds in Renewable Feedstocks Including $\mathrm{CO} 2$ and Biomass. ACS Publications.

23. Boretti, A. (2013). Renewable hydrogen to recycle $\mathrm{CO} 2$ to methanol. International Journal of Hydrogen Energy. 38(4): 1806-1812.

24. Babu, R. P., O'connor, K., \& Seeram, R. (2013). Current progress on bio-based polymers and their future trends. Progress in Biomaterials. 2(1):8.

25. Arora, A., \& Padua, G. (2010). Nanocomposites in food packaging. Journal of Food science. 75(1): R43-R49.
26. Polshettiwar, V., \& Varma, R. S. (2008). Greener and rapid access to bio-active heterocycles: onepot solvent-free synthesis of 1, 3, 4-oxadiazoles and 1, 3, 4-thiadiazoles. Tetrahedron Letters. 49(5): 879-883.

27. Vaddula, B. R., Varma, R. S., \& Leazer, J. (2013). Mixing with microwaves: Solvent-free and catalyst-free synthesis of pyrazoles and diazepines. Tetrahedron Letters. 54(12): 1538-1541.

28. Marvaniya, H. M., Modi, K. N., \& Sen, D. J. (2011). Greener reactions under solvent free conditions. Int J Drug Dev Res. 3(2):42-51.

29. Declerck, V., Nun, P., Martinez, J., \& Lamaty, F. (2009). Solvent- free synthesis of peptides. Angewandte Chemie International Edition, 48(49), 9318-9321.

30. Hailes, H. C. (2007). Reaction solvent selection: the potential of water as a solvent for organic transformations. Organic process research \& development. 11(1):114-120.

31. Yorimitsu, H., Nakamura, T., Shinokubo, H., Oshima, K., Omoto, K., \& Fujimoto, H. (2000). Powerful solvent effect of water in radical reaction: triethylborane-induced atom-transfer radical cyclization in water. Journal of the American Chemical Society,122(45), 1104111047.

32. Li, C. J. (1996). Aqueous Barbier-Grignard type reaction: scope, mechanism, and synthetic applications. Tetrahedron. 52(16): 5643-5668.

33. Shen, Z. L., Yeo, Y. L., \& Loh, T. P. (2008). Indium- copper and indium- silver mediated Barbier-Grignard-type alkylation reaction of aldehydes using unactivated alkyl halides in water. The Journal of organic chemistry. 73(10): 39223924.

34. Zhou, F., \& Li, C. J. (2019). En route to metalmediated and metal-catalysed reactions in water. Chemical science. 10(1): 34-46.

35. Romney, D. K., Arnold, F. H., Lipshutz, B. H., \& Li, C. J. (2018). Chemistry takes a bath: reactions in aqueous media.

36. Zhang, S., \& Gu, Y. (2018). Functionalized Ionic Liquid-based Catalytic Systems with Diversified Performance Enhancements, in Sustainable Catalysis: Energy-Efficient Reactions and Applications. 2018, Wiley-VCH Verlag Weinheim. 35-58.

37. Wiebe, A., Gieshoff, T., Möhle, S., Rodrigo, E., Zirbes, M., \& Waldvogel, S. R. (2018). Electrifying organic synthesis. Angewandte Chemie International Edition, 57(20), 5594-5619.

38. Kaur, N. (2018). Green synthesis of three-to fivemembered O-heterocycles using ionic liquids. Synthetic Communications. 48(13): 1588-1613.

39. Huang, W. C., Zhao, D., Guo, N., Xue, C., \& Mao, X. (2018). Green and facile production of chitin from crustacean shells using a natural deep eutectic solvent. Journal of agricultural and food chemistry, 66(45), 11897-11901. 
40. El Knidri, H., Belaabed, R., Addaou, A., Laajeb, A., \& Lahsini, A. (2018). Extraction, chemical modification and characterization of chitin and chitosan. International journal of biological macromolecules, 120, 1181-1189.

41. Nicolaou, K., \& Chen, J. S. (2009). The art of total synthesis through cascade reactions. Chemical Society Reviews. 38(11): 2993-3009.

42. de la Torre, M. C., \& Sierra, M. A. (2004). Comments on recent achievements in biomimetic organic synthesis. Angewandte Chemie International Edition. 43(2): 160-181.

43. Armenta, S., Garrigues, S., \& de la Guardia, M. (2008). Green analytical chemistry. TrAC Trends in Analytical Chemistry. 27(6): 497-511.

44. Yu, L. Y., \& Luo, Y. N. (2012). Discussion and Implementation of Constructing Green Organic Chemistry Laboratory. Guangzhou Chemical Industry. 19.

45. Zhou, X. B. (2013). Exploration on" Green Chemistry" experimental teaching in university. Laboratory Science. 2.

46. Cannon, A. S., \& Warner, J. C. (2011). The science of green chemistry and its role in chemicals policy and educational reform. NEW SOLUTIONS: A Journal of Environmental and Occupational Health Policy. 21(3): 499-517.

47. Clark, J. H., \& Macquarrie, D. J. (2008). Handbook of green chemistry and technology. John Wiley \& Sons.

48. Burmeister, M., Rauch, F., \& Eilks, I. (2012). Education for Sustainable Development (ESD) and chemistry education. Chemistry Education Research and Practice. 13(2): 59-68.

49. Burmeister, M., Schmidt-Jacob, S., \& Eilks, I. (2013). German chemistry teachers' understanding of sustainability and education for sustainable development-An interview case study. Chemistry Education Research and Practice. 14(2): 169-176.
50. Haack, J. A., \& Hutchison, J. E. (2016). Green chemistry education: 25 years of progress and 25 years ahead, ACS Publications.

51. Clark, J. H. (1999). Green chemistry: challenges and opportunities. Green Chemistry. 1(1): 1-8.

52. Wardencki, W., Curyło, J., \& Namiesśnik, J. (2005). Green Chemistry--Current and Future Issues. Polish Journal of Environmental Studies. 14(4).

53. Manley, J. B., Anastas, P. T., \& Cue Jr, B. W. (2008). Frontiers in Green Chemistry: meeting the grand challenges for sustainability in $R \& D$ and manufacturing. Journal of Cleaner Production. 16(6): 743-750.

54. Hjeresen, D. L., Anastas, P., Ware, S., \& Kirchhoff, M. (2001). Peer reviewed: green chemistry progress \& challenges.

55. Matus, K., Anastas, P. T., Clark, W. C., \& ItameriKinter, K. (2007). Overcoming the challenges to the implementation of green chemistry. CID Working Paper.

56. https://www.sigmaaldrich.com/chemistry/greeneralternatives.html.

57. Lipshutz, B. H., Taft, B. R., Abela, A. R., Ghorai, S., Krasovskiy, A., \& Duplais, C. (2012). Catalysis in the service of green chemistry: Nobel prizewinning palladium-catalysed cross-couplings, run in water at room temperature: Heck, Suzukimiyaura and Negishi reactions carried out in the absence of organic solvents, enabled by micellar catalysis. Platinum metals review, 56(2), 62.

58. Matus, K. J., Clark, W. C., Anastas, P. T., \& Zimmerman, J. B. (2012). Barriers to the implementation of green chemistry in the United States. Environmental science \& technology, 46(20), 10892-10899.

59. Lancaster, M. (2016). Green Chemistry 3rd Edition: An Introductory Text. Royal society of chemistry. 